\title{
QRS duration and cardiovascular mortality in Asian patients with heart failure and preserved and reduced ejection fraction
}

\author{
Jonathan Yap ${ }^{1 *}$, Yann Shan $\mathrm{Keh}^{1 *}$, Tong Shen ${ }^{1}$, Carolyn S.P. Lam ${ }^{1,3}$, Shaw Yang Chia ${ }^{1}$, \\ Fazlur Rehman Jaufeerally ${ }^{2,3}$, Wilson Ong ${ }^{1}$, David Sim ${ }^{1}$, Chi-Keong Ching ${ }^{1,3}$ \\ ${ }^{1}$ Department of Cardiology, National Heart Center Singapore, Singapore \\ ${ }^{2}$ Department of Internal Medicine, Singapore General Hospital, Singapore \\ ${ }^{3}$ Duke-NUS Graduate Medical School, Singapore
}

The QRS duration has been well established as a predictor of mortality in patients with heart failure with reduced ejection fraction (HFrEF) [1]. In patients with heart failure with preserved ejection fraction (HFpEF), some studies have shown that prolonged QRS duration has been associated with increased morbidity and mortality $[2,3]$. However, these studies were based mainly on Western cohorts with scarce data from Asia, where normal ranges for QRS duration may differ $[4,5]$. The aim of this study was to examine the association between QRS duration and mortality in an Asian heart failure cohort.

Consecutive patients who were admitted with heart failure as the primary diagnosis from two institutions from 1 January 2008 to 31 December 2009 were included. Those with paced rhythms were excluded. The QRS interval was measured by trained staff on a 12-lead electrocardiogram upon admission. HFpEF was defined as heart failure patients with ejection fraction $(\mathrm{EF}) \geq 50 \%$ and $\geq$ grade 1 diastolic dysfunction on the echocardiogram or N-terminal-pro-B-type natriuretic peptide (NT-proBNP) level $>220 \mathrm{pg} / \mathrm{mL}$ heart failure with nonpreserved $\mathrm{EF}$ ( $\mathrm{HFnpEF}$ ) was defined as $\mathrm{EF}<50 \%$. The outcomes were obtained from national registries. All patients were followed-up till December 2014. The primary outcomes were all-cause mortality and cardiovascular mortality. Ethics approval was obtained from the institutional review board.

Cox proportional hazard modelling was used to identify predictors of all-cause and cardiovas- cular mortality. Variables significant on univariate analysis $(\mathrm{p}<0.05)$ were selected for the multivariate models. Multivariate Cox proportional hazard models were then performed for each heart failure cohort to calculate hazard ratios (HR) and associated $95 \%$ confidence intervals (CI) for mortality. QRS duration was analyzed both as a continuous and categorical variable. The optimal QRS cut-off was assessed by area under receiver operating characteristics (AUROC) curve. Data was analyzed using the Statistical Package for the Social Sciences (SPSS $^{\oplus}$, version 23.0). A p value of $<0.05$ was taken to be statistically significant.

A total of $666 \mathrm{HFpEF}$ (mean age $73.1 \pm 10.5$, $36.3 \%$ male, mean LVEF $61 \pm 8 \%$ ) and 1032 HFnpEF (mean age $66.3 \pm 12.4$ years, $64.3 \%$ male, mean LVEF $29 \pm 13 \%$ ) were included. The clinical characteristics are summarized in Table 1.

In patients with HFpEF, 5-year overall and cardiovascular mortality was $57 \%(\mathrm{n}=381)$ and $28 \%(\mathrm{n}=189)$ respectively. QRS duration as a continuous variable was a significant predictor of cardiovascular (adjusted HR 1.010; 95\% CI 1.002-1.018; $\mathrm{p}=0.011$ ) but not overall mortality $(\mathrm{p}=0.190)$. A cut-off of $100 \mathrm{~ms}$ was found to provide the optimal discriminatory AUC compared to other cut-offs including $90 \mathrm{~ms}, 110 \mathrm{~ms}$ and $120 \mathrm{~ms}$. A $Q R S \geq 100 \mathrm{~ms}$ was a significant predictor of cardiovascular mortality (adjusted HR 1.468; 95\% CI 1.014-2.126; $\mathrm{p}=0.042$ ) but not overall mortality (adjusted HR 1.287; 95\% CI 0.993-1.668; $\mathrm{p}=0.056)$.

Address for correspondence: Dr. Jonathan Yap, National Heart Center Singapore, 5 Hospital Drive, Singapore 169609, tel: +65 67048965, fax: +65 68449069, e-mail: jonyap@yahoo.com

Received: 11.11.2019 Accepted: 9.03.2020

*Both authors contributed equally.

This article is available in open access under Creative Common Attribution-Non-Commercial-No Derivatives 4.0 International (CC BY-NC-ND 4.0) license, allowing to download articles and share them with others as long as they credit the authors and the publisher, but without permission to change them in any way or use them commercially. 
Table 1. Clinical characteristics of the study population.

\begin{tabular}{|c|c|c|c|c|c|c|}
\hline & \multicolumn{3}{|c|}{ Preserved ejection fraction $(n=666$ ) } & \multicolumn{3}{|c|}{ Reduced ejection fraction $(n=1032)$} \\
\hline & $\begin{array}{l}<100 \mathrm{~ms} \\
(\mathrm{n}=482)\end{array}$ & $\begin{array}{l}\geq 100 \mathrm{~ms} \\
(\mathrm{n}=184)\end{array}$ & $\mathbf{P}$ & $\begin{array}{l}<100 \mathrm{~ms} \\
(\mathrm{n}=484)\end{array}$ & $\begin{array}{l}\geq 100 \mathrm{~ms} \\
(\mathrm{n}=548)\end{array}$ & $\mathbf{P}$ \\
\hline \multicolumn{7}{|l|}{ Demographics } \\
\hline Mean age (SD) & $73.0(10.5)$ & $72.6(11.0)$ & 0.634 & $65.9(12.8)$ & $66.8(12.1)$ & 0.239 \\
\hline Male & $141(29.3 \%)$ & $101(54.9 \%)$ & $<0.001$ & $272(56.2 \%)$ & $394(71.9 \%)$ & $<0.001$ \\
\hline \multicolumn{7}{|l|}{ Race: } \\
\hline Chinese & $360(74.7 \%)$ & $136(73.9 \%)$ & 0.452 & $328(67.8 \%)$ & $372(67.9 \%)$ & 0.545 \\
\hline Malay & $55(11.4 \%)$ & $24(13.0 \%)$ & & $95(19.6 \%)$ & $94(17.2 \%)$ & \\
\hline Indian & $59(12.2 \%)$ & $18(9.8 \%)$ & & $51(10.5 \%)$ & $71(13.0 \%)$ & \\
\hline Others & $8(1.7 \%)$ & $6(3.3 \%)$ & & $10(2.1 \%)$ & $11(2.0 \%)$ & \\
\hline \multicolumn{7}{|l|}{ Clinical characteristics } \\
\hline Prior CAD & $204(42.3 \%)$ & $69(37.5 \%)$ & 0.258 & $193(39.9 \%)$ & $298(54.4 \%)$ & $<0.001$ \\
\hline Prior MI & $80(16.6 \%)$ & $34(18.5 \%)$ & 0.564 & $179(37.0 \%)$ & $210(38.3 \%)$ & 0.658 \\
\hline Atrial fibrillation & $164(34.0 \%)$ & $73(39.7 \%)$ & 0.173 & $94(19.4 \%)$ & $127(23.2 \%)$ & 0.142 \\
\hline Diabetes mellitus & $225(46.7 \%)$ & $86(46.7 \%)$ & 0.989 & $304(62.8 \%)$ & $277(50.5 \%)$ & $<0.001$ \\
\hline Hypertension & $388(80.5 \%)$ & $139(75.5 \%)$ & 0.159 & $324(66.9 \%)$ & $386(70.4 \%)$ & 0.226 \\
\hline Hyperlipidemia & $297(61.6 \%)$ & $96(52.2 \%)$ & 0.027 & $306(63.2 \%)$ & $355(64.8 \%)$ & 0.603 \\
\hline Stroke & $86(17.8 \%)$ & $36(19.6 \%)$ & 0.607 & $66(13.6 \%)$ & $78(14.2 \%)$ & 0.782 \\
\hline PVD & $24(5.0 \%)$ & $12(6.5 \%)$ & 0.431 & $35(7.2 \%)$ & $38(6.9 \%)$ & 0.853 \\
\hline COPD & $61(12.7 \%)$ & $30(16.3 \%)$ & 0.220 & $48(9.9 \%)$ & $74(13.5 \%)$ & 0.075 \\
\hline Ever smoker & $116(24.1 \%)$ & $67(36.4 \%)$ & 0.001 & $202(41.7 \%)$ & $279(50.9 \%)$ & 0.003 \\
\hline Systolic BP (SD) [mmHg] & $143.1(29.1)$ & $140.3(31.3)$ & 0.266 & $139.8(30.5)$ & $133.6(29.2)$ & 0.001 \\
\hline Diastolic BP (SD) [mmHg] & $73.2(16.5)$ & $72.4(17.5)$ & 0.608 & $80.6(19.3)$ & $75.6(18.3)$ & $<0.001$ \\
\hline Heart rate (SD) & $84.4(22.9)$ & $78.8(22.9)$ & 0.005 & $92.8(21.0)$ & $84.4(18.3)$ & $<0.001$ \\
\hline QRS duration (SD) & $85.1(8.1)$ & $115.7(17.5)$ & $<0.001$ & $87.9(7.6)$ & $123.9(24.2)$ & $<0.001$ \\
\hline NT-proBNP (SD) [pg/mL] & $\begin{array}{c}5079.9 \\
(7141.8)\end{array}$ & $\begin{array}{c}8282.3 \\
(11909.7)\end{array}$ & 0.061 & $\begin{array}{c}11741.1 \\
(14600.0)\end{array}$ & $\begin{array}{c}12389.6 \\
(15358.1)\end{array}$ & 0.537 \\
\hline Creatinine (SD) $[\mu \mathrm{mol} / \mathrm{L}]$ & $121.4(84.8)$ & $145.9(125.3)$ & 0.015 & $133.4(98.4)$ & $141.2(92.7)$ & 0.186 \\
\hline Sodium (SD) [mmol/L] & $136.4(4.9)$ & $136.2(5.2)$ & 0.706 & $136.0(7.3)$ & $135.8(8.7)$ & 0.713 \\
\hline Potassium (SD) [mmol/L] & $4.2(0.8)$ & $4.2(0.8)$ & 0.451 & $4.3(0.8)$ & $4.3(1.8)$ & 0.895 \\
\hline Hemoglobin (SD) [g/dL] & $11.7(2.0)$ & $12.0(2.1)$ & 0.085 & $12.4(2.1)$ & $12.6(2.0)$ & 0.046 \\
\hline \multicolumn{7}{|l|}{ Discharge medications } \\
\hline ACEI/ARB & $284(58.9 \%)$ & $114(62.0 \%)$ & 0.475 & $360(74.4 \%)$ & $415(75.7 \%)$ & 0.617 \\
\hline Beta-blocker & $240(49.8 \%)$ & $98(53.3 \%)$ & 0.423 & $314(64.9 \%)$ & $369(67.3 \%)$ & 0.405 \\
\hline $\begin{array}{l}\text { Spironolactone/Aldosterone } \\
\text { antagonist }\end{array}$ & $35(7.3 \%)$ & $17(9.2 \%)$ & 0.395 & $90(18.6 \%)$ & $145(26.5 \%)$ & 0.003 \\
\hline Nitrate & 192 (39.8\%) & $84(45.7 \%)$ & 0.173 & $245(50.6 \%)$ & $312(56.9 \%)$ & 0.042 \\
\hline Diuretic & $365(75.7 \%)$ & $148(80.4 \%)$ & 0.176 & $424(87.6 \%)$ & $476(86.9 \%)$ & 0.722 \\
\hline Digoxin & 88 (18.3\%) & $37(20.1 \%)$ & 0.584 & $130(26.9 \%)$ & $158(28.8 \%)$ & 0.481 \\
\hline ASA & $196(40.7 \%)$ & $87(47.3 \%)$ & 0.122 & $282(58.3 \%)$ & $331(60.4 \%)$ & 0.485 \\
\hline Clopidogrel & $63(13.1 \%)$ & $16(8.7 \%)$ & 0.118 & 89 (18.4\%) & $90(16.4 \%)$ & 0.405 \\
\hline Warfarin & 86 (17.8\%) & $33(17.9 \%)$ & 0.978 & $52(10.7 \%)$ & $70(12.8 \%)$ & 0.313 \\
\hline Lipid-lowering & $301(62.4 \%)$ & $112(60.9 \%)$ & 0.707 & $357(73.8 \%)$ & $395(72.1 \%)$ & 0.545 \\
\hline
\end{tabular}

CAD - coronary artery disease; $\mathrm{MI}$ - myocardial infarction; PVD - peripheral vascular disease; COPD — chronic obstructive pulmonary disease; BP - blood pressure; NT-proBNP - N-terminal-pro-B-type natriuretic peptide; ACEI/ARB - angiotensin converting enzyme/angiotensin receptor blocker; ASA — acetylsalicylic acid 
In patients with HFnpEF, 5-year overall and cardiovascular mortality was $65 \%(\mathrm{n}=673)$ and 43.0\% ( $\mathrm{n}=444)$. QRS duration as a continuous variable was a significant predictor of both overall (adjusted HR 1.005; 95\% CI 1.001-1.008; $\mathrm{p}=0.004$ ) and cardiovascular mortality (adjusted HR 1.006; 95\% CI 1.002-1.010; $\mathrm{p}=0.003$ ). A cut-off of $100 \mathrm{~ms}$ was found to provide the optimal discriminatory AUC compared to other cut-offs including $90 \mathrm{~ms}, 110 \mathrm{~ms}$ and $120 \mathrm{~ms}$. QRS $\geq 100 \mathrm{~ms}$ was a significant predictor of both overall (adjusted HR 1.262; 95\% CI 1.047-1.522; p = 0.015) and cardiovascular mortality (adjusted HR 1.336; 95\% CI 1.058-1.688; $\mathrm{p}=0.015$; Table 2).

In this Asian HFnpEF cohort, it was found that QRS prolongation predicted both overall and cardiovascular mortality. This is in-line with current literature [1] and lends further evidence to the detrimental impact of $\mathrm{QRS}$ prolongation across different ethnicities.

Of greater interest are the results from the HFpEF cohort. In two non-Asian studies, QRS prolongation in $\mathrm{HFpEF}$ impacted upon overall mortality $[2,3]$. In one of the few Asian studies to-date, Gisberts found a significant association of QRS duration on overall mortality in HFrEF patients, but not in HFpEF patients [4]; cardiovascular mortality was not assessed. The neutral all-cause mortality finding was similar to that of our HFpEF cohort. However, a significant relationship with cardiovascular mortality was additionally found in the HFpEF patients of the current study. This is pathophysiologically plausible with $\mathrm{QRS}$ prolongation indicative of cardiac abnormalities [6]. Of note, the cut-offs in the above two non-Asian studies was found to be $120 \mathrm{~ms}$ [2,3]; a cut-off of $100 \mathrm{~ms}$ to was found have greater discriminatory value in the Asian cohort. This may be a result of body size or ethnicity $[4,5]$. It was found that the average QRS duration in a healthy community-based cohort of Chinese, Malays and Indians was $89 \mathrm{~ms}$ in males and $83 \mathrm{~ms}$ in female [5]. In the Framingham heart study, the average QRS duration in a healthy Caucasian male was $97 \mathrm{~ms}$ and $87 \mathrm{~ms}$ in females [7]. Several studies have shown that increasing body size results in increasing QRS duration [5] and this may account for the lower QRS cut-offs as seen in the present study with known smaller body sizes of Asians. The differences in findings between the current HFpEF and HFnpEF cohort are likely the result of both conditions being separate disease entities. Multiple studies have previously shown distinct clinical and prognostic differences between these groups [8].

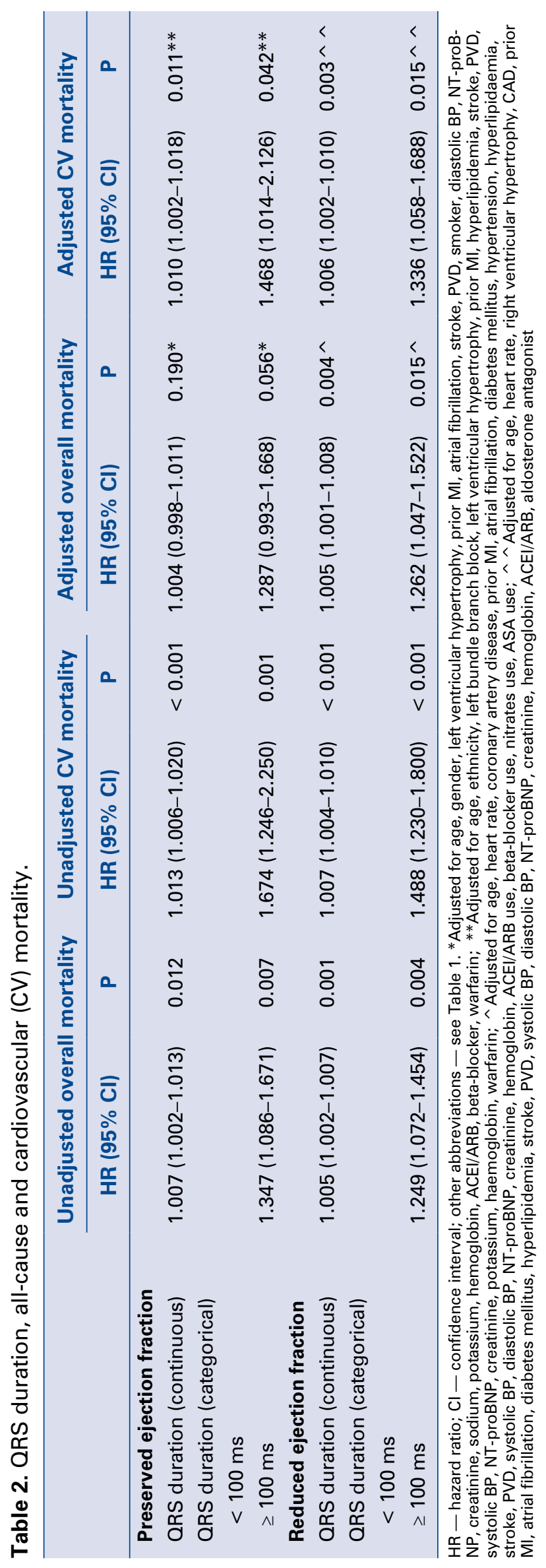


HFpEF remains a difficult clinical condition to manage due to its limited therapeutic options. Risk stratification is challenging and has fewer established prognostic markers [9]. An electrocardiogram is readily available and thus QRS duration could potentially be used as a simple risk stratification tool for clinicians. QRS prolongation has been linked to mechanical desynchrony in HFpEF [10]. In appropriate HFrEF patients, the use of cardiac resynchronization therapy has been shown to provide mortality and symptomatic benefit, but how this eventually translates to therapeutic options for $\mathrm{HFpEF}$ is less clear. Regardless, $\mathrm{HFpEF}$ patients with prolonged QRS duration identifies a subset at higher risk of adverse outcomes; greater efforts must be taken to optimize the holistic care of these patients including control of cardiovascular risk factors.

Limitations of the present study include primary use of hospitalized patients with heart failure; more stable patients in an outpatient/community setting may have been different. Secondly, the current cohort consisted of patients who were mainly of Chinese, Malay and Indian ethnicity which reflects the population distribution in Singapore; the data should be validated in other Asian ethnicities. Thirdly, the uptake of guideline directed medical therapy in the present cohort reflects real-world practice and this cohort was recruited from 2008 to 2009; the potential impact of heart failure therapies, especially the more contemporary medications, will be the work of future studies. Lastly, the QRS duration was only available from the admission electrocardiogram. Changes in QRS duration over time was not captured.

In the present Asian heart failure cohort, QRS duration is a significant predictor of cardiovascular mortality in both HFpEF and HFnpEF patients. QRS duration also significantly predicted overall mortality in HFnpEF patients.

Conflict of interest: None declared

\section{References}

1. Hofmann M, Bauer R, Handrock R, et al. Prognostic value of the QRS duration in patients with heart failure: a subgroup analysis from 24 centers of Val-HeFT. J Card Fail. 2005; 11(7): 523-528, doi: 10.1016/j.cardfail.2005.03.008, indexed in Pubmed: 16198248.

2. Lund LH, Jurga J, Edner M, et al. Prevalence, correlates, and prognostic significance of QRS prolongation in heart failure with reduced and preserved ejection fraction. Eur Heart J. 2013; 34(7): 529-539, doi: 10.1093/eurheartj/ehs305, indexed in Pubmed: 23041499.

3. Hummel SL, Skorcz S, Koelling TM. Prolonged electrocardiogram QRS duration independently predicts long-term mortality in patients hospitalized for heart failure with preserved systolic function. J Card Fail. 2009; 15(7): 553-560, doi: 10.1016/j.cardfail.2009.02.002, indexed in Pubmed: 19700130.

4. Gijsberts CM, Benson L, Dahlström U, et al. Ethnic differences in the association of QRS duration with ejection fraction and outcome in heart failure. Heart. 2016; 102(18): 1464-1471, doi: 10.1136/heartjnl-2015-309212, indexed in Pubmed: 27402805.

5. Tan ESJ, Yap J, Xu CF, et al. Association of age, sex, body size and ethnicity with electrocardiographic values in community-based older asian adults. Heart Lung Circ. 2016; 25(7): 705-711, doi: 10.1016/j.hlc.2016.01.015, indexed in Pubmed: 26935158.

6. Wang NC, Maggioni AP, Konstam MA, et al. Clinical implications of QRS duration in patients hospitalized with worsening heart failure and reduced left ventricular ejection fraction. JAMA. 2008; 299(22): 2656-2666, doi: 10.1001/jama.299.22.2656, indexed in Pubmed: 18544725.

7. Levy D, Bailey JJ, Garrison RJ, et al. Electrocardiographic changes with advancing age. A cross-sectional study of the association of age with QRS axis, duration and voltage. J Electrocardiol. 1987; 20 Suppl: 44-47, indexed in Pubmed: 3500994.

8. Yap J, Sim D, Lim CP, et al. Predictors of two-year mortality in Asian patients with heart failure and preserved ejection fraction. Int J Cardiol. 2015; 183: 33-38, doi: 10.1016/j.ijcard.2015.01.063, indexed in Pubmed: 25662051.

9. Burke MA, Katz DH, Beussink L, et al. Prognostic importance of pathophysiologic markers in patients with heart failure and preserved ejection fraction. Circ Heart Fail. 2014; 7(2): 288-299, doi: 10.1161/CIRCHEARTFAILURE.113.000854, indexed in Pubmed: 24365774.

10. Santos ABS, Kraigher-Krainer E, Bello N, et al. Left ventricular dyssynchrony in patients with heart failure and preserved ejection fraction. Eur Heart J. 2014; 35(1): 42-47, doi: 10.1093/ eurheartj/eht427, indexed in Pubmed: 24164863. 